\title{
Finite Element Modeling of Low Heat Conducting Building Bricks
}

\author{
Oluleke Oluwole*, Jacob Joshua, Henry Nwagwo \\ Department of Mechanical Engineering, University of Ibadan, Ibadan, Nigeria \\ Email: *lekeoluwole@gmail.com
}

Received April 3, 2012; revised May 13, 2012; accepted June 9, 2012

\begin{abstract}
Heat conduction through conventional and interlocking building bricks with cavities was studied in this work. Heat transfer analysis was carried out using $\mathrm{MATLAB}^{\circledR}$ partial differential equation toolbox. Regular and staggered hole arrangements were studied. Results showed that four staggered holed interlocking bricks were effective in thermal resistance into the bricks and increasing the holes beyond four did not give any thermal resistance advantage. For the conventional bricks staggered holes did not give any thermal resistance advantage but the four-holed bricks were also adjudged to be effective in thermal resistance into the brick surface. Increasing the number of holes beyond four in conventional bricks did give some thermal resistivity advantage but very minimal. Structural strengths of holed bricks were not considered in this study.
\end{abstract}

Keywords: Building Bricks; Finite Element Modeling; Heat Conduction

\section{Introduction}

The conventional old form of building bricks in the tropics with two rectangular cavities are known for their high heat conduction property which causes so much discomfort in homes especially in hot and arid areas of the world. From an economic and environmental conservation point of view, it is more beneficial to design buildings with high thermal insulation characteristics than the old practice currently followed in the construction of buildings. This will result in long-term benefit of reducing the cost of cooling as well as reducing the pollution of the environment due to heavy use of fuel. Use of double skin walls with insulating materials like chip boards contributes to some extent in reducing the high cost of air conditioning in summer. These materials due to their high cost are limited to government offices and commercial complexes. However, in residential buildings, schools and other constructions, the use of such systems is not recognized and the traditional method of construction is still dominant. It is well known that the thermal conductivity of concrete is much higher than the thermal conductivity of air. By introducing holes or air-gaps in the concrete block, the thermal conductivity of concrete block can be greatly reduced.

Lacarrier et al. [1] analyzed numerically the vertically perforated bricks. They reported that walls can be constructed without any other materials than clay and mortar.

"Corresponding author.
They reported that heat transfer in these assemblies is not totally understood. For perforated brick construction, it is indicated that convection heat transfer is negligible in the perforations. Therefore, the thermal resistance of the brick increases. In a particular study of the ruptures it is concluded that the convection present in these regions is a local phenomenon since it breaks the thermal bridges created by the mortar fill.

Bajorek and Lloyd [2] carried out an experimental study to investigate the natural convection heat transfer within a two dimensional partitioned enclosure of unit aspect ratio using an interferometer. They reported that dividing the cavity along its 5th European Thermal-Sciences Conference, The Netherlands, 2008 vertical axis results in a reduction in the heat transfer by approximately $15 \%$.

Nishimura et al. [3] reported that Nusselt number is inversely proportional to the number of partitions which was also confirmed by experiments. They also observed that effective heat leak reduction is attained using $2-5$ partitions.

Aviram et al. [4] investigated experimentally variable aspect ratio cavity and reported that increasing aspect ratio decreases flow magnitude, reduces circulation intensity and increases the cavity thermal resistance. Nusselt number diminished with reduced cavity depth.

Recently, del Coz Diaz et al. [5] carried out an experimental and numerical study to investigate the thermal transmittance coefficient, U, of a wall made of Arliblock 
bricks. They observed that wall insulation decreases with the increase in the mortar and material conductivities. They also noticed that changing the profiles of the holes alters the rate of the heat transfer through the hollow blocks. Then, they studied major variables influencing the thermal conductivity of masonry materials and carried out an optimization study for different brick geometries based on both thermal resistance and weight [6].

The minimum web thickness for safe construction was reported by Kumar [7]. Ciofalo and Karayiannis [8] reported that the mechanism responsible for the large reduction in heat transfer in partitioned enclosures was because of the breaking down of the unicellular circulation near the regions.

Manz [9] studied natural convection heat transfer in rectangular, gas-filled tall cavities in building elements such as insulating glazing units, double-skin facades and others. He reported that flow regimes depend on $\mathrm{Ra}$ and the aspect ratio. A linear temperature profile exists as a function of the $x$-position within the so-called conduction regime.

Al-Hazmy [10] investigated the heat transfer through a common hollow building brick. Insulation assessment of the building blocks was examined based upon the heat transfer rate. Three different configurations for building bricks were studied including a gas-filled and insulationfilled cavity. Results show that the cellular air motion inside blocks' cavities contributes significantly to the heat loads. The insertion of polystyrene bars reduced the heat rate by a maximum of $36 \%$.

Lee and Pessiki [11] carried out a study to investigate the performance characteristics of precast concrete sandwich wall panels with two or three wythes separated by air layers. It was found that, in general, the thermal performance of three-wythe panels is better than that of twowythe panels due to the increased thermal path length.

Ho and Yih [12] analyzed conjugate natural convection and conduction in a multi-layer wall. They considered isothermal left and right sides of the wall and adiabatic boundary condition in both top and bottom surfaces.

Tong and Gerner [13] analyzed natural convection in partitioned air-filled rectangular enclosures and reported that placing a partition midway between the vertical walls results in the greatest reduction in heat transfer.

Kangni et al. [14] investigated natural convection in partitioned walls for various aspect ratios and for a wide range of $\mathrm{Ra}$ and wall thicknesses. Turkoglu and Yucel [15] investigated numerically natural convection heat transfer in enclosures with conducting multiple partitions and side walls. However, in their analysis the sidewalls were assumed to be isothermal, thus eliminating the temperature gradient in the $y$-direction within the solid. They also kept the top and bottom surfaces perfectly in- sulated. They reported that Nusselt decreases as the number of partitions is increased up to 4 . They also reported that the cavity aspect ratio had an insignificant effect on their calculations.

Lorente [16] published a review article to illustrate the heat flow through walls with relatively complicated internal structure. He reported the effect of Rayleigh number and aspect ratio showing that for $\mathrm{Re}=3550$, no fluctuations were observed and a unicellular flow was observed. As the Rayleigh number increases, the flow becomes multi-cellular.

Antar and Thomas [17] addressed the heat transfer across a hollow building block and estimated two dimensional effects of the heat transfer across the block. In another study [18] they developed a numerical finite-difference analysis for steady-state heat transfer in a composite wall with a two-dimensional rectangular gray body radiating cavity with and without natural convection circulation of air. The purpose of their analysis was to provide a basis for evaluating the accuracy of the first-order two-dimensional model. Recently, Antar [19] investigated the significance of multi-dimensional effects in estimating the rate of heat loss and identified the cases where simple one-dimensional convection/radiation analysis may be considered a good approximation for heat transfer rate calculations.

It was reported by Antar and Thomas [17,18] and Antar [19] that the approximate simple one dimensional analysis for the problem under investigation had two alternative thermal circuits, an upper bound thermal circuit and a lower bound one. Calculations showed that the percentage difference in estimating the upper bound and lower bound heat transfer rate reaches 39\%. This indicated significant two dimensional effects. Neither the upper bound nor the lower bound solution provided reliable value for the heat leak, and a two dimensional model was seen to be needed to estimate the heat transfer rate accurately. Therefore, another work at developing and using a two-dimensional model for investigating the effect of cavities layout on the thermal resistance of the block was done using a block of 5 cavities. The study showed that the shape and distribution of the cavity played an equally important role in thermal resistance.

As the number of holes or air-gaps is increased, the thermal conductivity is reduced. Therefore, this paper focuses on the development of blocks with different arrangements of holes, which are characterized by good thermal resistance.

\section{Methodology}

The basic geometries under consideration are presented in Figures 1 and 2. This problem was solved by heat transfer by conduction whereas the cavities were as- 
sumed to be vacuum. That is, there was no heat transfer by convection in the cavities. Ordered and scattered hole layouts were considered. The geometry modeling and meshing are shown in Figures $\mathbf{3}$ and $\mathbf{4}$ respectively.

\subsection{Regular Bricks}

Dimensions:

$$
\begin{array}{ll}
\mathrm{w}_{1}=0.05 \mathrm{~m} & \mathrm{w}_{2}=0.06 \mathrm{~m} \\
\mathrm{~L}_{1}=0.05 \mathrm{~m} & \mathrm{~L}_{2}=0.15 \mathrm{~m}
\end{array}
$$

\section{Boundry Conditions:}

Heat flux $(\mathrm{g})=h * T_{\infty}=375\left(\mathrm{~W} / \mathrm{m}^{2}\right)$.

Heat transfer coefficient $(q)=h=15\left(\mathrm{~W} / \mathrm{m}^{2} \cdot{ }^{\circ} \mathrm{C}\right)$.

where, $h$ is the conduction heat transfer coefficient, $T_{\infty}$ is the ambient temperature of the

Brick, Density $(\rho)=1922 \mathrm{~kg} / \mathrm{m}^{3}$, Heat capacity $\mathrm{C}=$ $0.79 \mathrm{KJ} / \mathrm{kg} \cdot{ }^{\circ} \mathrm{C}$.

Coefficient of heat conduction $(\mathrm{K})=0.72 \mathrm{~W} / \mathrm{m} \cdot{ }^{\circ} \mathrm{C}$.

Assumptions:

- Temperature at the entrance of heat is assumed to be $40^{\circ} \mathrm{C}$.

- Temperature at other sides had Neumann condition of zero.

- No heat transfer by convection. Therefore, convective heat transfer coefficient $(h)$ is zero.

- Transient state conditions.

- Constant properties.

- No heat generation within the brick.

\subsection{Interlocking Bricks}

$\mathrm{w}_{1}=0.05 \mathrm{~m}, \mathrm{w}_{2}=0.1, \mathrm{~L}_{1}=0.05 \mathrm{~m}, \mathrm{~L}_{2}=0.2 \mathrm{~m}$

Boundry Conditions:

Heat flux $(g)=h * T_{\infty}=375\left(\mathrm{~W} / \mathrm{m}^{2}\right)$.

Heat transfer coefficient $(q)=h=15\left(\mathrm{~W} / \mathrm{m}^{2} \cdot{ }^{\circ} \mathrm{C}\right)$ where; $h$ is the convection heat transfer coefficient or film conductance.

$T_{\infty}$ is the ambient temperature of the brick, Density $(\rho)$ $=2300 \mathrm{~kg} / \mathrm{m}^{3}$,

Heat capacity $\mathrm{C}=0.960 \mathrm{KJ} / \mathrm{kg} \cdot{ }^{\circ} \mathrm{C}$, Coefficient of heat conduction $(\mathrm{K})=0.3 \mathrm{~W} / \mathrm{m} \cdot{ }^{\circ} \mathrm{C}$.

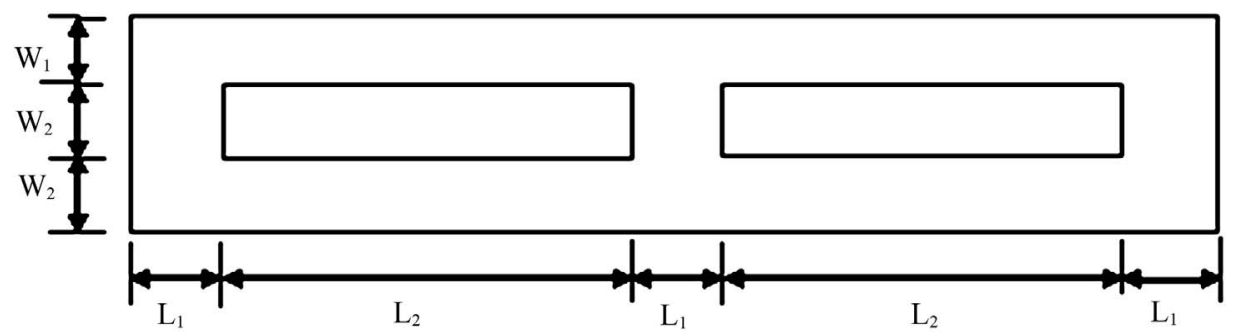

(a)

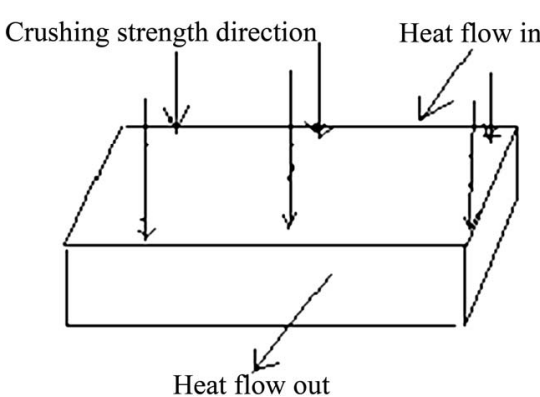

(b)

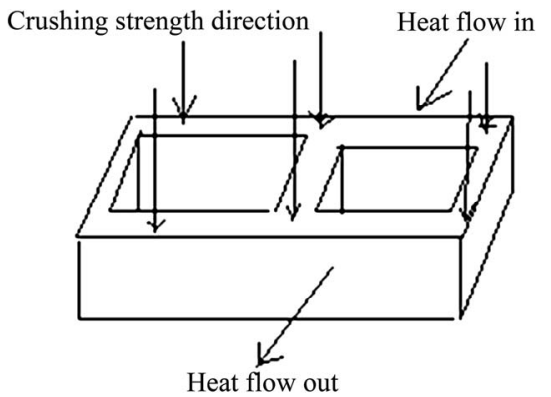

(c)

Figure 1. (a) Regular Hollow brick geometry; (b) Monolithic brick; (c) Geometry of regular hollow bricks.

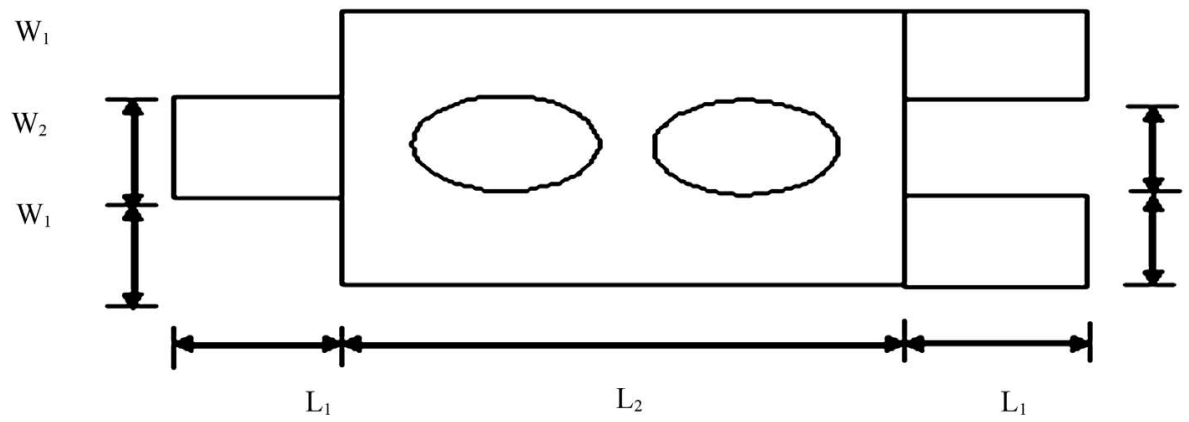

Figure 2. Hollow interlocking brick geometry. 


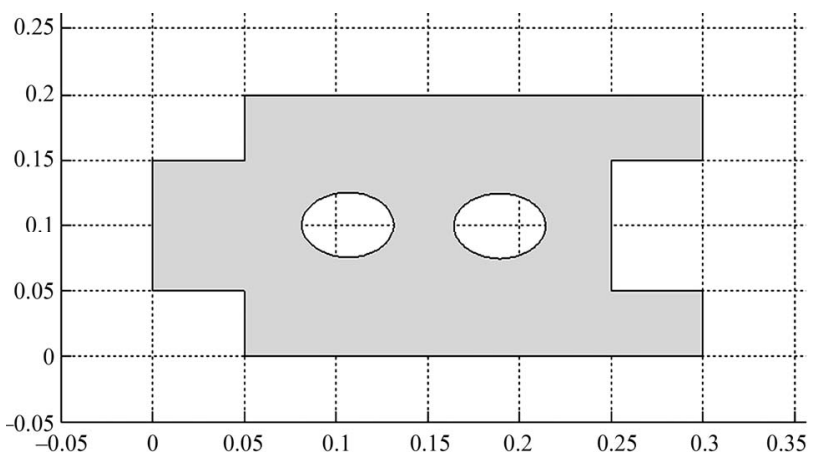

Figure 3. Geometry modeling of interlocking bricks with 2-cavities.

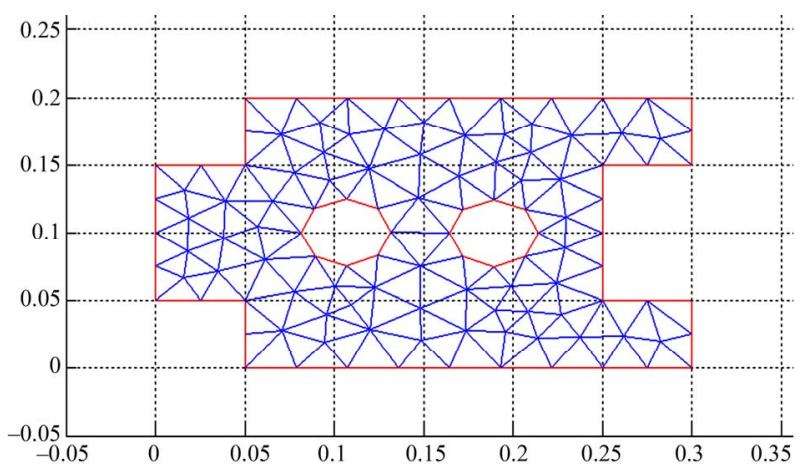

Figure 4. Meshing the interlocking brick domain.

\subsection{Governing Equation}

One-dimensional conduction heat transfer in the block solid material is governed by the following equation:

Let the density of the brick be $\rho$, Specific heat $c$, and area of the brick normal to the direction of heat transfer is $A$.

An energy balance on the brick during a small time interval $\Delta t$ can be expressed as

Rate of heat conduction through

$=$ Rate of change of the energy the brick in $y$-direction content of the element (brick)

or

$$
\dot{Q}_{y}=\frac{\Delta E_{\text {brick }}}{\Delta t}
$$

where,

$$
\begin{aligned}
\Delta E_{\text {brick }} E_{t+\Delta t}-E_{t} & =m c\left(T_{t+\Delta t}-T_{t}\right) \\
& =\rho c A \Delta y\left(T_{t+\Delta t}-T_{t}\right)
\end{aligned}
$$

Substituting Equation (3) into Equation (2):

$$
Q_{y}=\rho c A \Delta y \frac{T_{t+\Delta t}-T_{t}}{\Delta t}
$$

Dividing Equation (4) by $A \Delta y$

$$
\frac{1}{A} \frac{\dot{Q}_{y}}{\Delta y}=\rho c \frac{T_{t+\Delta t}-T_{t}}{\Delta t}
$$

Taking the limit as $\Delta y \rightarrow 0$ and $\Delta t \rightarrow 0$ yields

$$
\frac{1}{A} \frac{\partial}{\partial y}\left(k A \frac{\partial T}{\partial y}\right)=\rho c \frac{\partial T}{\partial t}
$$

But since the area $A$ is constant, the one-dimensional transient heat conduction equation for the brick becomes

$$
\frac{\partial}{\partial y}\left(k \frac{\partial T}{\partial y}\right)=\rho c \frac{\partial T}{\partial t}
$$

Or, where $k$ is constant

$$
k \frac{\partial^{2} T}{\partial y^{2}}=\rho c \frac{\partial T}{\partial t}
$$

or

$$
\frac{\partial^{2} T}{\partial y^{2}}=\frac{1}{\alpha} \frac{\partial T}{\partial t}
$$

\section{Results and Discussion}

Figures 5-10 show the results of the models of different cases of transient heat transfer in building bricks with cavities, subjected to the same ambient temperature to study the temperature variation across the brick from the outside to the inside of the building. These results show the effect of the cavities in building bricks.

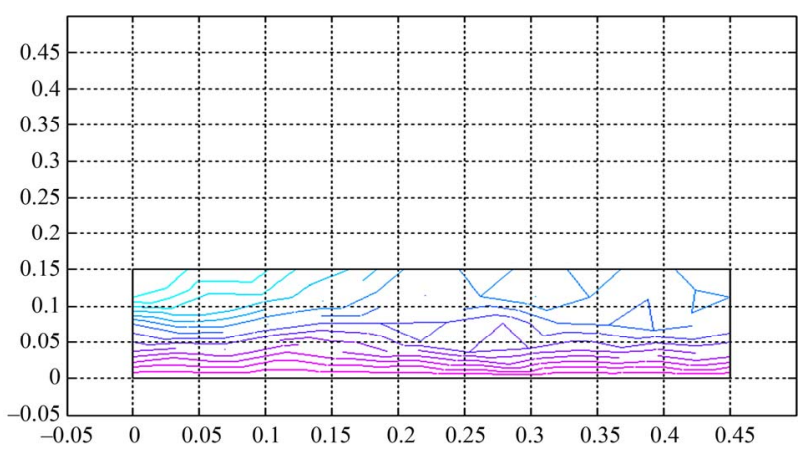

(a)

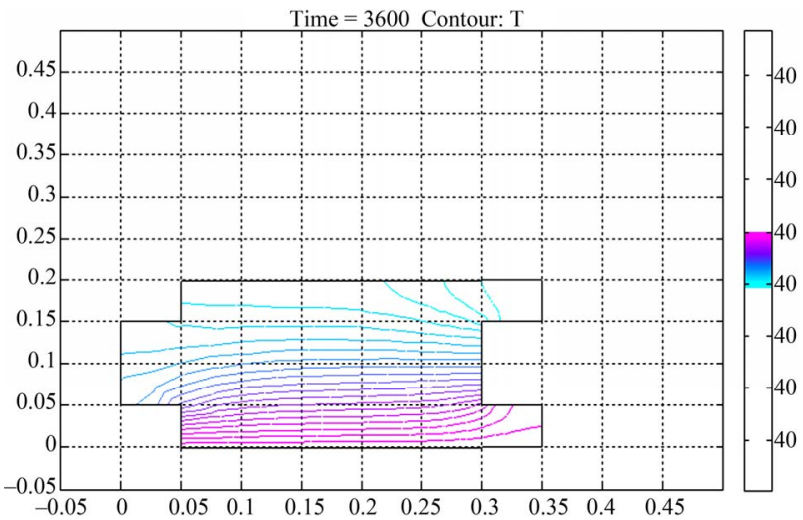

(b)

Figure 5. (a) Model of a Solid conventional building brick; (b) Model of a Solid interlocking building brick. 
Figures 5(a) and (b) show the solid bricks heated at $y$ $=0 \mathrm{~mm}$ to $40^{\circ} \mathrm{C}$, and held at that temperature for 8 hours on the side representing the outside of a room wall which was initially at ambient temperature of $25^{\circ} \mathrm{C}$. After 8 hours of application of heat at a temperature of $40 \mathrm{deg} \cdot \mathrm{C}$, the inside of the bricks had risen to a temperature of 40 $\operatorname{deg} \cdot \mathrm{C}$. This equality in the temperatures outside and inside the wall shows the scenario in a building; since all the heat are conducted from outside the brick to the inside of the brick showing the level of discomfort that can be experienced in the inside of a building with solid bricks.

Figures 6(a) and (b) show results for two-cavitied bricks. The temperature at the inner part of the bricks had reduced to $26.22^{\circ} \mathrm{C}$ and $26.88^{\circ} \mathrm{C}$ for conventional and interlocking bricks respectively.

Taking the analysis further to four-cavity bricks (Figures $7(a)$ and (b)), the temperature dropped further on the inside to $25.43^{\circ} \mathrm{C}$ and $25.3^{\circ} \mathrm{C}$ for conventional and interlocking bricks respectively. This showed the increasing resistance to heat flow with increasing cavities in the bricks. The reduction in heat transfer with increasing cavities was more pronounced in the interlocking brick.

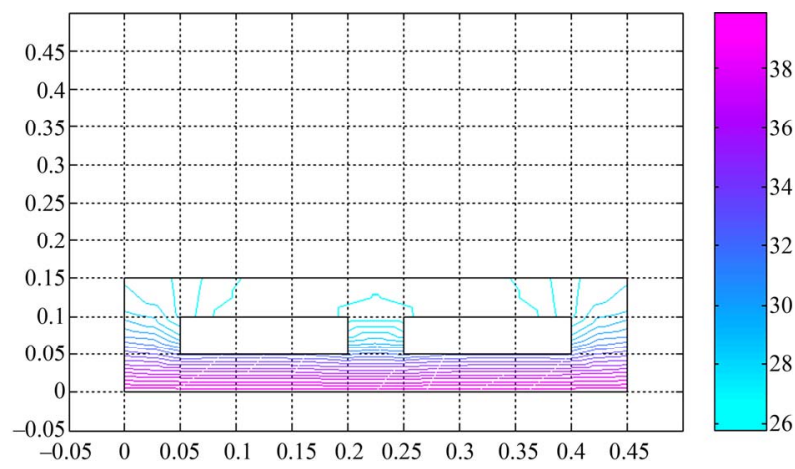

(a)

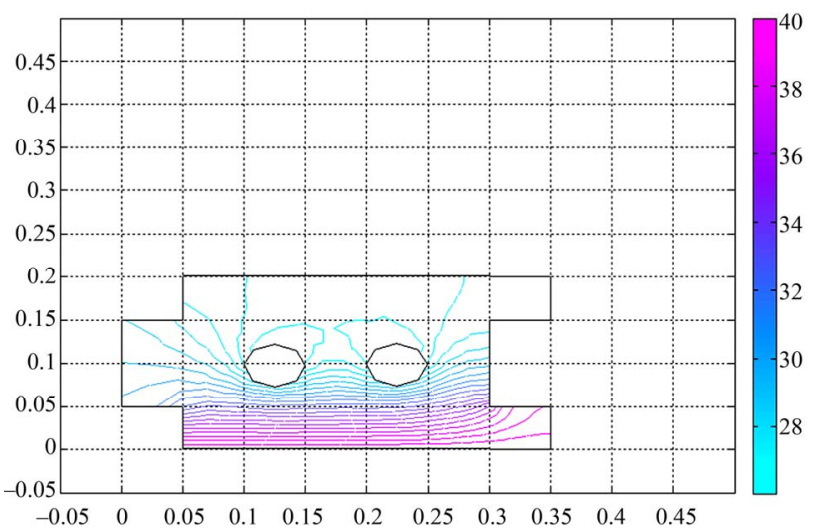

(b)

Figure 6. (a) Heat transfer in conventional building brick with 2 cavities in 8 hours; (b) Heat transfer in interlocking brick with 2 cavities in 8 hours.

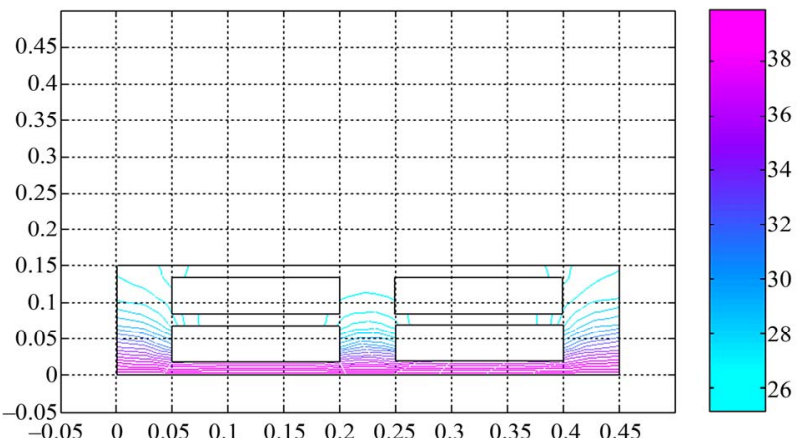

(a)

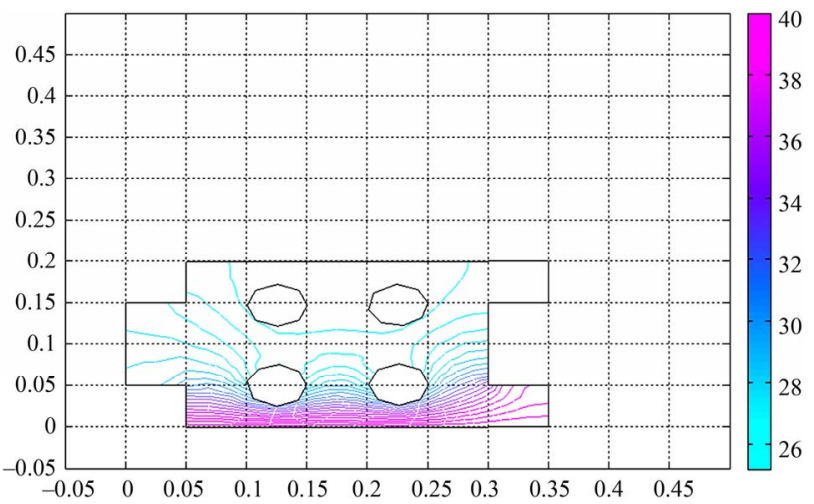

(b)

Figure 7. (a) Heat conduction in conventional building brick with 4 cavities in 8 hours; (b) Heat conduction in interlocking brick with 4 cavities in 8 hours.

Increasing the cavities further still to eight holes in the conventional brick (Figures 8(a)) did not show any appreciable increase in resistance to heat transfer over the four-cavity conventional brick as the temperature at the inside wall decreased minimally to $25.3^{\circ} \mathrm{C}$. However, for the interlocking brick (Figure 8(b)) there was an appreciable increase in thermal resistance to the extent that over an 8 hour period, the inside wall temperature did not increase and was kept at the ambient temperature of 25 $\operatorname{deg} \cdot \mathrm{C}$.

\section{Case of Staggered Hole Arrangements}

Figures 9(a) and (b) show the results of heat conduction in interlocking and conventional bricks with four staggered cavities. There was appreciable effect of the hole staggering on thermal resistance for interlocking brick (Figure 9(a)). There was enough thermal resistance over an 8 hour period to keep the inside of the brick at the ambient temperature of $25 \mathrm{deg} \cdot \mathrm{C}$. However, for the conventional brick there was no advantage as the temperature was $25.45 \mathrm{deg} \cdot \mathrm{C}$ showing a rise in temeperature of $0.02 \mathrm{deg} \cdot \mathrm{C}$ over the ordered hole arrangement.

Increasing further the number of holes in the staggered arrangement (Figures 10(b)), showed significant effect on thermal conductivity in the conventional brick. Inside 
wall temperature reduced to $25.03 \mathrm{deg} \cdot \mathrm{C}$. Increasing the cavities to 8 in interlocking bricks (Figure 10(a)) was not necessary as the ambient temperature was maintained as in the four-cavitied staggered arrangement. However, it was observed that the heat within the brick was kept almost within the first third of the brick.

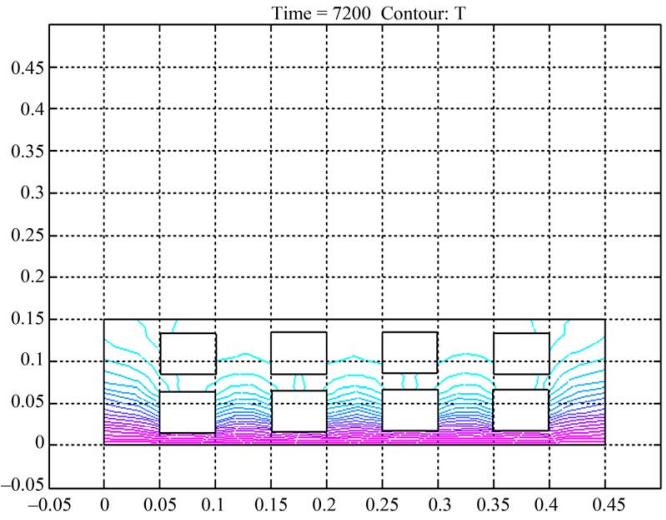

(a)
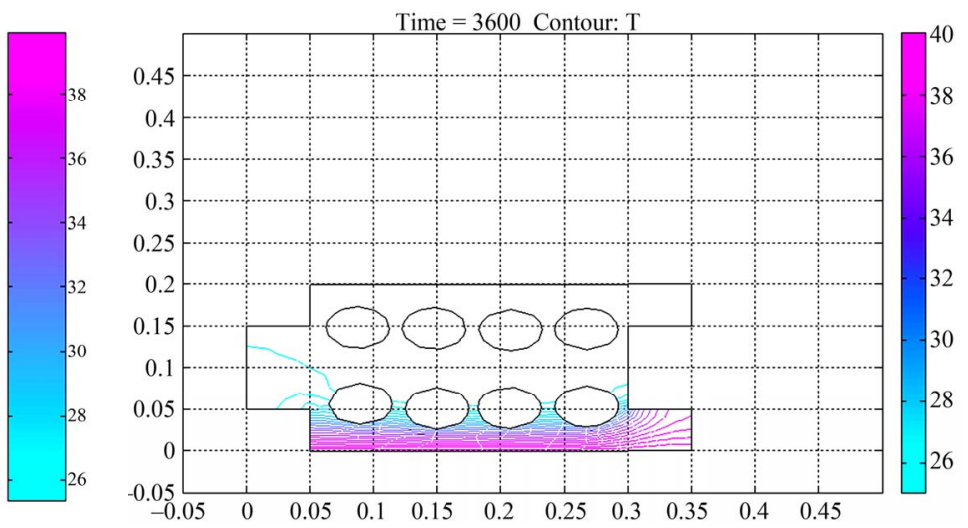

(b)

Figure 8. (a) Heat transfer in conventional building brick with 8 cavities in 8 hours; (b) Heat transfer in interlocking brick with 8 cavities in 8 hours.

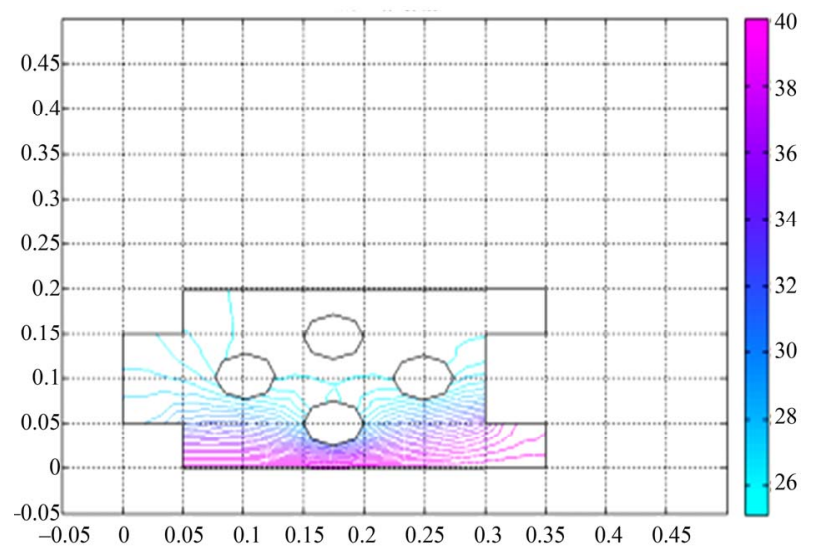

(a)

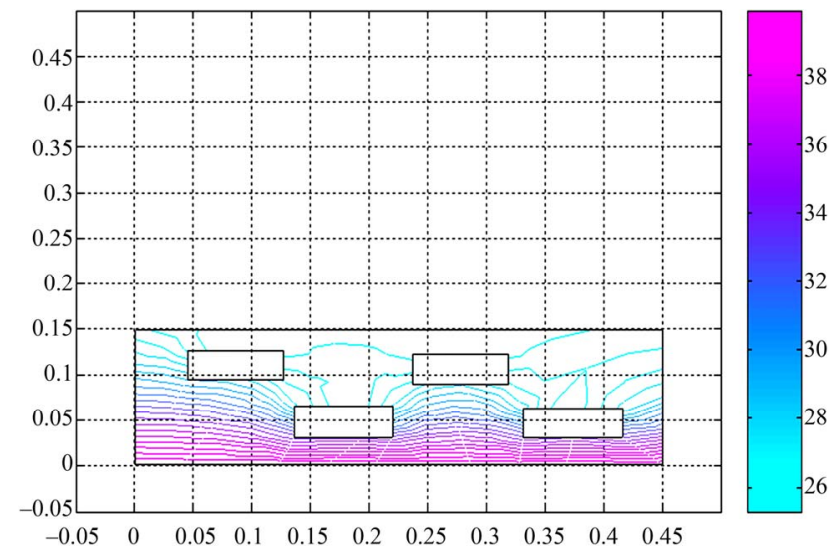

(b)

Figure 9. (a) Heat conduction in interlocking brick with 4 cavities in 8 hours; (b) Heat conduction in conventional building brick with 4 cavities in 8 hours.

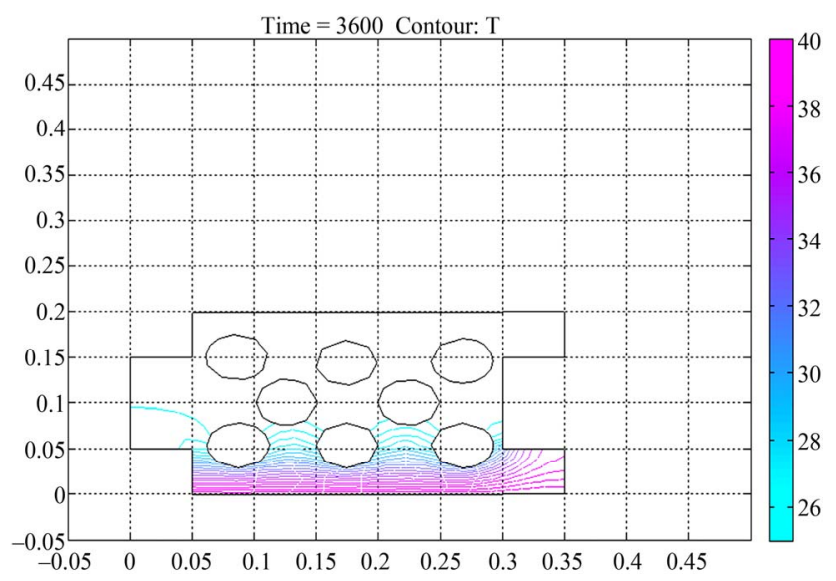

(a)

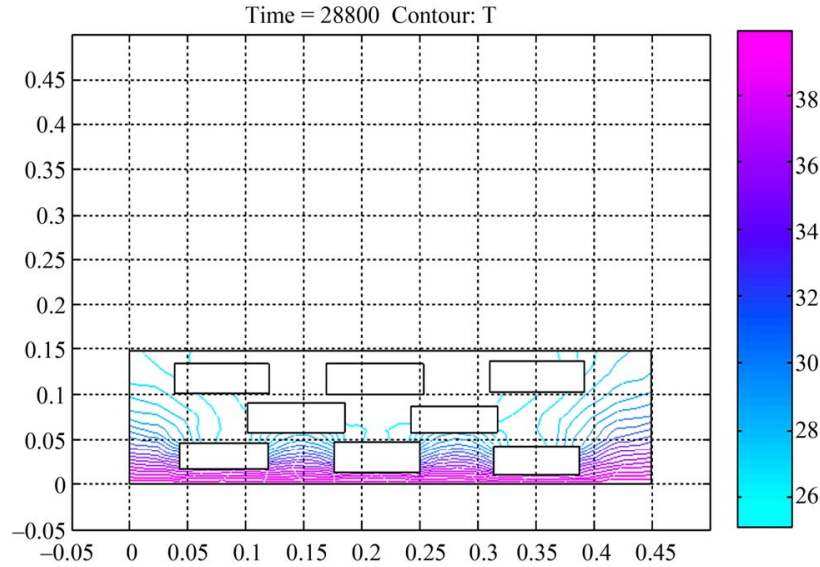

(b)

Figure 10. (a) Heat conduction in interlocking brick with 8 cavities in 8 hours; (b) Heat conduction in conventional building brick with 8 cavities in 8 hours. 


\section{Conclusions}

Conduction heat transfer within ordinary (conventional) and interlocking bricks with hollow cavities was investigated.

In conventional bricks, increasing the number of cavities played a substantial role in decreasing heat flow into the building and hence enhanced thermal insulation. After the four-hole arrangement, increasing the number of holes only gave marginal thermal resistance over the four-hole arrangement.

In the case of interlocking bricks, it was observed that staggered hole arrangement helped in decreasing heat flow into the brick wall. Four-staggered-hole arrangement gave the same thermal resistance as an ordered eight-hole arrangement. The 8-hole brick arrangement may also tend to compromise the strength of the brick.

\section{REFERENCES}

[1] B. Lacarrière, B. Lartigue and F. Monchoux, "Numerical Study of Heat Transfer in a Wall of Vertically Perforated Bricks: Influence of Assembly Method," Energy and Buildings, Vol. 35, No. 3, 2003, pp. 229-237. doi:10.1016/S0378-7788(02)00049-X

[2] S. M. Bajorek and J. R. Lloyd, "Experimental Investigation of Natural Convection in partitioned Enclosures," Journal of Heat Transfer, Vol. 104, No. 3, 1982, pp. 527531. doi:10.1115/1.3245125

[3] T. Nishimura, M. Shiraishi, F. Nagasawa and Y. Kawamura, "Natural Convection Heat Transfer in Enclosures with Multiple Vertical Partitions," International Journal of Heat and Mass Transfer, Vol. 31, No. 8, 1988, pp. 1679-1686. doi:10.1016/0017-9310(88)90280-3

[4] D. P. Aviram, A. N. Fried and J. J. Roberts, "Thermal Properties of a Variable Cavity Wall," Building and Environment, Vol. 36, No. 9, 2001, pp. 1057-1072. doi:10.1016/S0360-1323(00)00042-1

[5] J. J. del Coz Diaz, P. J. Garcia Nieto, A. Martin Rodriguez, A. L. Martinez-Luengas and C. BetegonBiempica, "Non-Linear Thermal Analysis of Light Concrete Hollow Brick Walls by the Finite Element Method and Experimental Validation," Applied Thermal Engineering, Vol. 26, No. 8-9, 2006, pp. 777-786. doi:10.1016/j.applthermaleng.2005.10.012

[6] J. J. del Coz Díaz, P. J. García Nieto, C. Betegón Biempica and M. P. Prendes Gero, "Analysis and Optimization of the Heat-Insulating Light Concrete Hollow Brick Walls Design by the Finite Element Method," Applied Thermal Engineering, Vol. 27, No. 8-9, 2007, pp. 14451456doi:10.1016/j.applthermaleng.2006.10.010

[7] S. Kumar, "Fly Ash-Lime-Phosphogypsum Hollow Blocks for Walls and Partitions," Building and Environment, Vol. 38, No. 2, 2003, pp. 291-295. doi:10.1016/S0360-1323(02)00068-9
[8] M. Ciofalo and T. G. Karayiannis, "Natural Convection Heat Transfer in a Partially_Or Completely_Partitioned Vertical Rectangular Enclosure," International Journal of Heat and Mass Transfer, Vol. 34, No. 1, 1991, pp. 167179. doi:10.1016/0017-9310(91)90184-G

[9] H. Manz, "Numerical Simulation of Heat Transfer by Natural Convection in Cavities of Facade Elements," Energy and Buildings, Vol. 35, No. 3, 2003, pp. 305-311. doi:10.1016/S0378-7788(02)00088-9

[10] M. M. Al-Hazmy, "Analysis of Coupled Natural Convection Conduction Effects on the Heat Transport through Hollow Building Blocks," Energy and Buildings, Vol. 38, No. 5, 2006, pp. 515-521. doi:10.1016/j.enbuild.2005.08.010

[11] B. J. Lee and S. Pessiki, "Thermal Performance Evaluation of Precast Concrete Three-Wythe Sandwich Wall Panels," Energy and Buildings, Vol. 38, No. 8, 2006, pp. 1006-1014. doi:10.1016/j.enbuild.2005.11.014

[12] C. J. Ho and Y. L. Yih, "Conjugate Natural Convection Heat Transfer in an Air-Fileld Rectangular Cavity," International Communication in Heat and Mass Transfer, Vol. 14, No. 1, 1987, pp. 91-100. doi:10.1016/0735-1933(87)90011-X

[13] T. W. Tong and F. M. Gerner, "Natural Convection in Partitioned Air-Filled Rectangular Enclosures," International Communication in Heat and Mass Transfer, Vol. 13, No. 1, 1986, pp. 99-108. doi:10.1016/0735-1933(86)90076-X

[14] A. Kangni, B. Yedder and E. Bilgen, "Natural Convection and Conduction in Enclosures with Multiple Vertical Partitions," International Journal of Heat and Mass Transfer, Vol. 34, No. 1, 1991, pp. 2819-2825. doi:10.1016/0017-9310(91)90242-7

[15] H. Torkoglu and N. Yucel, "Natural Convection Heat Transfer in Enclosures with Conducting Multiple Partitions and Side Walls," Heat and Mass Transfer, Vol. 2, No. 1-2, 1996, pp. 1-8. doi:10.1007/s002310050084

[16] S. Lorente, "Heat Losses through Building Walls with Closed, Open and Deformable Cavities," International Journal of Energy Research, Vol. 26, No. 7, 2002, pp. 611-632. doi:10.1002/er.807

[17] M. A. Antar and L. C. Thomas, "Heat Transfer through a Composite Wall with Enclosed Spaces: A Practical TwoDimensional Analysis Approach," ASHRAE Transactions, Vol. 106, 2001, pp. 318-324.

[18] M. A. Antar and L. C. Thomas, "Heat Transfer through a Composite Wall with an Evacuated Rectangular Gray Body Radiating Space: A Numerical Solution," ASHRAE Transactions, Vol. 110, No. 2, 2004, pp. 36-45.

[19] M. A. Antar, "Multi-Dimensional Effects in Estimating the Heat Loss across Building Envelopes," Proceedings of the 2nd International Conference on Thermal Engineering Theory and Applications, Al-Ain, 3-6 January 2006. 